\title{
LETRAMENTO NA EDUCAÇÃO INFANTIL: COMO A PSICANÁLISE PODE AJUDAR?
}

\section{LITERACY IN THE CHILDREN EDUCATION: HOW CAN THE PSYCHOANALYSIS HELP IT?}

\author{
Francisco Neto Pereira Pinto 1 \\ Solene Borges Gonçalves ${ }^{2}$ \\ Maria do Espírito Santo L. S. Oliveira ${ }^{3}$
}

\begin{abstract}
Resumo: O presente artigo propõe uma reflexão sobre o processo de letramento na educação infantil, indagando sobre como a Psicanálise pode contribuir para que o aluno, na leitura e na escrita, possa realmente aprender fazer. Para tanto, são mobilizadas as teorias do campo do letramento e da psicanálise freudolacaniana. Algumas conclusões a que chegamos foi que o educador precisa implicar o aluno em seu aprendizado, ou seja, leva-lo a ler e a escrever, efetivamente, fazendo frente a um comportamento pautado pela lei do menor esforço. Por outro lado, a aluno precisa aceitar o convite e colocar de si em seu aprendizado, sem a esperança de que poderá aprender a ler e a escrever apenas a partir das explicações do professor. Deverá entender que aprenderá fazer, fazendo e, a partir, se lançar na aventura do letramento.
\end{abstract}

Palavras-chave: letramento; psicanálise; educação infantil.

Abstract: This article proposes a reflection on the literacy process in children's education, asking how psychoanalysis can contribute so that the student, in reading and writing, can actually learn to do. For that, the theories of the field of literacy and of Freudolacanian psychoanalysis are mobilized. Some conclusions that we have reached are that the educator needs to involve the student in his / her learning, that is, it leads him / her to read and to write, effectively, facing a behavior ruled by the law of the least effort. On the other hand, the student must accept the invitation and place himself in his learning, without the hope that he can learn to read and write only from the teacher's explanations. You will understand that you will learn to do, to do, and, starting from, to embark on the adventure of literacy.

Keywords: literacy; psychoanalysis; child education.

\section{Introdução}

Neste trabalho, vamos falar sobre o letramento na educação infantil, sobre como se dá esse processo e qual a contribuição da Psicanálise freudo-lacaniana para que ele ocorra de forma significativa para a criança. Considerando a leitura e a escrita como partes fundamentais da vida das pessoas nas sociedades grafocêntricas, entendemos ser importante

\footnotetext{
${ }^{1}$ Doutor em Letras pela Universidade Federal do Tocantins. Professor de Língua Portuguesa e Metodologia da Pesquisa no UNITPAC. E-mail: fneto@uft.edu.br

${ }^{2}$ Graduada em Pedagogia. E-mail: solleny-enfermagem@ hotmail.com

${ }^{3}$ E-mail: nenemaezona@gmail.com
} 
levar o aluno a se inserir nesse mundo munido de recursos suficientes para lidar com a escrita e a leitura de maneiras satisfatórias, o que se coloca como condição necessária para o exercício da cidadania e o gozo de uma vida digna. Posto isso, estabelecemos como objetivo deste trabalho compreender quais condições concorrem para o aprender a ler e a escrever de maneira relevante. Para nos guiar por essa reflexão, elaboramos a seguinte pergunta norteadora: como o educador pode implicar o aluno, levando-o a desenvolver o letramento, em busca de um percurso que realmente faça sentido para o seu para o aprendizado? É nesse ponto da reflexão que a Psicanálise poderá nos ajudar.

O interesse pelo letramento surgiu a partir do momento em que duas das autoras deste trabalho, em seu processo de formação, observaram como pessoas, mesmo alfabetizadas, isto é, sabendo ler e escrever, denunciam, em diversas situações, dificuldades em ler e escrever com desenvoltura, ou seja, mostram não ter domínio, na prática, quanto ao saber fazer. Assim, analisando o letramento como prática social, buscamos entender como pode ser inserido na educação infantil e como pode contribuir para o desenvolvimento das crianças quanto ao saber fazer relacionado à escrita, desde logo cedo, evitando, assim, a patologia do analfabetismo funcional.

Em nossa prática de estágio supervisionado, realizado como atividade obrigatória do Curso de Pedagogia, de um Centro Universitário localizado na cidade de Araguaína, Tocantins, região Norte do Brasil, a partir do sexto semestre, observamos que o letramento não tem sido uma constante nas salas de aula da alfabetização por nós observadas. Contudo, isso não se deve à má vontade dos professores, pois observamos que, no geral, buscam alfabetizar letrando. Porém, a preocupação em cumprir com tudo que é estabelecido para o currículo escolar leva-os a trabalhar os conteúdos de maneira apressada, o que, do nosso ponto de vista, isso pode dificultar o desencadeamento do letramento no processo de alfabetização escolar.

No campo da leitura, no geral, observamos que o plano de aula não contempla períodos de leitura de textos que instiguem a curiosidade das crianças, visando lançar bases para a criação de histórias de leitura. De fato, as leituras realizadas em sala de aula são apenas de textos dos livros didáticos, cujo trabalho de exploração se limita a interpretações superficiais e, muitas vezes, destinado apenas à resolução de atividades propostas pelo próprio livro. Se o letramento é o uso da leitura e da escrita nas práticas sociais, como a criança pode desenvolvê-lo se o que lhe é apresentado é tão limitado? Do ponto de vista do trabalho com a 
escrita também não presenciamos práticas minimamente arrojadas o suficiente para instaurar a apropriação desse saber fazer por parte dos alunos, dado que uma vez ou outra eram instigados a continuar uma história. Não se tratava, como se pode intuir, de uma atividade diária, com objetivo de incentivar a escrita. Entendemos que, se essa não for uma prática constante, a escola não conseguirá formar alunos capazes de fazer uso da escrita em seu meio social. Dito isso, cumpre estabelecer que nosso referencial teórico é composto, do ponto de vista do letramento, pelos trabalhos de Magda Soares (1998; 2003; 2017), Leda Tfouni (2005) e Luiz Carlos Cagliari (1998). Pelo prisma da Psicanálise, orientamo-nos por autores psicanalistas como Jacques Lacan (1998) e Jorge Forbes (2012).

\section{Sobre o letramento}

Letramento é um termo relativamente novo no âmbito educacional brasileiro. Uma das primeiras aparições desse conceito é atribuída a Mary Kato, em seu livro No Mundo da Escrita: uma perspectiva psicolinguística (1986). Para a autora, a língua falada culta "é consequência do letramento" (KATO, 1986, apud SOARES, 1998, p. 15). Letramento é um termo complexo e que não tem uma única definição, mas que nos leva a pensar a importância cada vez mais crescente que a escrita alfabética foi galgando nas sociedades ocidentais desde a invenção da imprensa pelo alemão Johannes Gutenberg, no século XV. Magda Soares (2003) lapida o conceito de letramento sob vários ângulos, entendendo-o, contudo, como um saber do qual o sujeito se apropria e mediante o qual age nas mais diferentes esferas da vida na sociedade. Nos termos da autora, o letramento se refere às

\footnotetext{
habilidades de interpretar e produzir diferentes tipos e gêneros de textos, habilidades de orientar-se pelos protocolos de leitura que marcam o texto ou de lançar mão desses protocolos, ao escrever; atitudes de inserção efetiva no mundo da escrita, tendo interesse e prazer em ler e escrever, sabendo utilizar a escrita para encontrar ou fornecer informações e conhecimentos, escrevendo ou lendo de forma diferenciada, segundo as circunstâncias, o objetivos, o interlocutor (SOARES, 2003, p. 92).
}

Luiz Carlos Cagliari (1998), em seu livro Alfabetizando Sem o BÁ-BÉ-BI-BÓ-BU, explica que a condição de alfabetizado não implica necessariamente à de letrado. Para o autor, uma pessoa alfabetizada é aquela que sabe ler e escrever, já um indivíduo letrado é aquele que vive em estado de letramento, não só sabendo ler e escrever, mas fazendo uso social da leitura e da escrita, atendendo adequadamente às demandas e práticas às sociais. Em suas próprias palavras: 
já compreendemos que nosso problema não é apenas ensinar nossas crianças a ler e a escrever, mas é também, e sobretudo, levar os indivíduos - crianças e adultos — a fazer uso da leitura e da escrita, envolver-se em práticas sociais de leitura e de escrita (CAGLIARI, 1998, p. 58).

Para o autor, como podemos perceber, o trabalho em sala de aula não deve se limitar a ensinar apenas a ler e a escrever, dada a necessidade de se criar condições para que os alfabetizados possam imergir em um ambiente de letramento, em um mundo letrado, ou seja, em um mundo em que as pessoas tenham acesso a diferentes modos de leitura e de escrita, utilizando-se dos variados gêneros textuais em diversos locais, tais como bibliotecas, livrarias etc. O objetivo é que o aluno aprenda a ler e a escrever e que possa realmente fazer isso de maneira satisfatória dentro e fora da escola, ou seja, quando e onde isso for necessário. $\mathrm{Na}$ escola, deve-se oportunizar ao educando viver a experiência e o trabalho de aquisição de hábitos de leitura e de escrita cujas consequências seja o empoderamento para o exercício da cidadania e não apenas o cumprimento de exigências e rotinas escolares.

\section{Alfabetização e letramento}

Alfabetização é definida como o processo de aprender a ler e a escrever, ou seja, refere-se à aquisição da tecnologia de escrita, a um conjunto de técnicas envolvidas na aprendizagem de como a língua escrita funciona. Como diz Soares (2003), trata-se da aquisição do conjunto de técnicas que são exigidas pela prática da leitura e da escrita:

\footnotetext{
As habilidades de codificação de fonemas em grafemas e de decodificação de grafemas em fonemas, isto é, o domínio do sistema de escrita (alfabético, ortográfico); as habilidades motoras de manipulação de instrumentos e equipamentos para que a codificação e decodificação se realizem, isto é, a aquisição de modos de escrever e de modos de ler; [...] habilidades de escrever ou ler, seguindo a direção correta da escrita na página (de cima para baixo, da esquerda para a direita) [...] (SOARES, 2003, p. 91).
}

Esse conjunto de habilidades e aquisições relacionam-se à aprendizagem inicial da língua, mas circunscrita a uma faceta específica, ou seja, não recobre toda a aprendizagem necessária para o bom desempenho no uso da língua dentro e fora da escola. Para Soares (2017, p. 28), a alfabetização, então, aponta para a "faceta propriamente linguística da língua escrita - a representação visual da cadeia sonora da fala", o que é muito importante para que a pessoa saiba ler e escrever, mas que não assegura, por si só, que esteja preparada para fazê-lo nas mais diversas situações da vida quando necessário. Por outro lado, o letramento caracteriza-se pelo uso social da leitura e da escrita, ou seja, vai além da aquisição da tecnologia, pois é o uso dessas práticas, de modo efetivo e satisfatório, para inserir-se na 
sociedade como um cidadão, com direitos e deveres. Trata-se, portanto, de um saber-fazer com a língua escrita, de fato.

Podemos dizer que um indivíduo é considerado alfabetizado quando domina a leitura e a escrita e, para que o aluno possa conseguir alcança-lo, o professor alfabetizador deve inserir em suas aulas a diversidade de textos e de gêneros, proporcionando, assim, ao educando, por meio de materiais concretos e da prática interdisciplinar, a integração de diferentes saberes. $\mathrm{O}$ educador, ao alfabetizar, deve levar em conta o histórico de cada aluno e as situações por ele vividas nas relações diárias, respeitando as expressões da realidade social em que vive, com vistas ao desenvolvimento do letramento. Nesse contexto, é importante que a escola inclua as diversas maneiras de trabalhar o letramento como prática social, para o desenvolvimento da identidade, formação e autonomia do sujeito, para que ele não fique apenas como a aquisição da leitura e da escrita.

Do ponto de vista da alfabetização, quando o educando consegue distinguir que cada som representa, normalmente, uma letra, quando, por exemplo, compreende que o grafema $b$ corresponde ao fonema /b/, ele está alfabetizado. Nesse processo, aprende que, para escrever, precisa de uma técnica, como segurar o lápis, a caneta, a borracha, além de compreender que a escrita se inicia da esquerda para a direita, de cima para baixo, e que para a leitura existe uma posição correta do livro. A essas habilidades motoras e ao domínio dessas técnicas chamamos alfabetização (SOARES, 2003). Podemos dizer, ainda, que se trata de um processo de construção de hipóteses sobre o sistema alfabético de escrita no qual o aluno precisa participar de situações desafiadoras que lhe oportunizem a reflexão sobre a língua escrita.

Por meio da interação com objetos do conhecimento é que o educando vai construindo essas hipóteses, de forma progressiva. Contudo, não é suficiente o mero convívio com o material escrito, mas são necessários direcionamento e sistematização derivados da reflexão metalinguística, ou seja, da reflexão sobre a própria escrita. Para isso, deve-se partir de textos reais para que a alfabetização seja concebida como uma construção conceitual e contínua, podendo ser desenvolvida dentro e fora da sala de aula. Para Emília Ferreiro e Ana Teberosky (1999), independente da classe social em que o indivíduo esteja inserido, ele percorre caminhos para se apropriar da língua escrita, passando por níveis estruturais de pensamento denominados nível pré-silábico, nível silábico, nível silábico-alfabético e nível alfabético. Não vamos nos deter nesses níveis, mas queremos destacar a importância de se garantir que 
desde os níveis mais iniciais o aluno viva uma alfabetização que tenha como alvo desencadear o processo de letramento.

Importante ressaltar que estamos entendendo letramento como a apropriação que o indivíduo faz da linguagem escrita na perspectiva de um saber fazer, de modo que possa compreender o significado do que lê e escreve, ou seja, quando essa tecnologia é utilizada para informar, informar-se, interagir com outros e orientar-se. O processo de letramento, de acordo com Soares (2017), envolve duas outras facetas, a interativa e a sociocultural, que podem assim ser entendidas:

\footnotetext{
a faceta interativa da língua escrita - a língua escrita como veículo de interação entre as pessoas, de expressão e compreensão de mensagens; a faceta sociocultural da língua escrita - os usos, funções e valores atribuídos à escrita em contextos socioculturais (SOARES, 2017, p. 29 - ênfases no original).
}

Como se percebe, do ponto de vista do letramento a língua escrita é vista mais do que como uma tecnologia, já que é também um sistema simbólico por meio do qual os sujeitos interagem e seus usos nunca são inocentes. Para o aluno, portanto, é importante, mais do que apenas a ler e escrever, que saiba também como fazer de maneira adequada e aceitável do ponto de vista dos usos sociais. Não entendemos, é bom ressaltar, que o letramento seja um estado pronto e acabado ao qual o sujeito alcança de uma vez para sempre. Trata-se, por outro lado, de um processo que jamais acaba e, quanto mais o sujeito avança, mais horizontes haverá aos quais pode se lançar. Dito assim, fica claro que, da perspectiva a qual nos filiamos, letramento e alfabetização são processos distintos e, ao mesmo tempo, inseparáveis, dado que, dentro da sala de aula, ambos podem acontecer de maneira simultânea. Eventos de letramento podem, porém, ocorrer para além da sala de aula. Nessa perspectiva, Tfouni (2005, p. 21) afirma que "os estudos do letramento não se restringem somente àquelas pessoas que adquiriram a escrita, isto é, aos alfabetizados'. Nossa reflexão, porém, restringe-se aos processos de alfabetização e letramento que se desenvolvem nas salas de aula escolares.

\section{Contribuição da Psicanálise para o processo de letramento}

Dado o já exposto, surge a questão: qual seria uma possível contribuição da Psicanálise ao processo de letramento? Antes de passarmos a uma possível resposta, cumpre consignar que nosso foco se direciona para o trabalho do professor frente ao processo de alfabetização e de letramento na sala de aula. Nesse sentido, uma das maneiras de pensarmos essa contribuição é levando em consideração o que em Psicanálise se chama implicação. Do 
ponto de vista clínico, implicar o paciente significa levá-lo a perceber que a escrita de sua história leva sua assinatura e, do ponto de vista do letramento, significa levar o aluno a perceber que seu aprendizado só pode ocorrer mediante sua participação ativa, ou seja, de que não é possível aprender a ler e a escrever e a fazer usos sociais desses aprendizados sem sua implicação efetiva. O conhecimento não se transfere, por osmose, do professor para o aluno, o que significa dizer que o aluno precisa trabalhar, e muito, se há de construir, com a ajuda do professor, seu próprio letramento.

Dito de outro modo, é o aluno quem constrói seu próprio saber, e o educador é o mediador dessa aprendizagem e precisa, portanto, pensar na responsabilidade do próprio aluno frente a construção desse saber-fazer. Vamos exemplificar essa contribuição da Psicanálise à prática do professor por meio de caso freudiano. Sigmund Freud, no caso Dora, Fragmentos da análise de um caso de histeria, trabalha a implicação subjetiva de sua paciente quando, na verdade, tudo o que ela queria era se queixar de sua situação na vida, o que envolvia culpabilizar por seu mal-estar a sua família e um casal, amigos de seus pais. Segundo o texto, a paciente de Freud, Dora, era uma moça de dezoito anos de idade que foi encaminhada a ele por seu pai. A análise durou apenas três meses, tendo início em outubro, e fim, por abandono da paciente, em dezembro do mesmo ano de 1900. Dora vivia com a família, composta por sua mãe, seu irmão e seu pai, ao qual ela era mais próxima, tornando-se amiga e confidente dele. A família de Dora tem fortes laços de amizade com a família K. Seu pai, por ser uma pessoa bastante enferma, aproxima-se mais ainda da Sra. K., por ela lhe oferecer cuidados e, dada essa proximidade, acabam se envolvendo em um caso amoroso. $\mathrm{O}$ Sr. K, esposo da Sra. K, corteja Dora, despertando na moça um sentimento de ódio e repugnância por ele.

O pai de Dora, que ela tanto amava, mesmo sabendo do que lhe acontecia, ignorava o comportamento do Sr. K, usando a moça como uma moeda de troca em seu caso com a Sra. K. Toda essa desordem desenvolveu em Dora um grande desinteresse pela própria vida, do que resultou planejar um suicídio. Dora, então, é levada até Freud, pelo pai, para tratar a histeria. Ela faz várias queixas e culpa a todos por essa grande desordem em sua vida. Freud, percebendo essa tendência, por meio de seu manejo da análise, é como se dissesse: qual é sua própria parte na desordem de que você se queixa?. Pela maneira como conduz o tratamento, podemos entender que Freud implica Dora para que ela se responsabilize pela parte que lhe cabe da situação e não fique se vendo como uma completa vítima, uma vez que ela gosta de 
ser paquerada pelo Sr. K e adota um comportamento ativo em toda a situação que envolve as duas famílias. Sobre a conduta de Freud no caso Dora, o psicanalista francês Jacques Lacan, em seus Escritos, diz:

Ele obriga Dora a constatar que, da grande desordem do mundo de seu pai, cujo estrago constitui o objeto de sua reclamação, ela faz mais do que participar; que ela se constituiu a cavilha dessa desordem, e que não poderia continuar sem sua complacência (LACAN, 1998, p. 602).

Conforme ponto de vista de Lacan, Dora não apenas participava como também era complacente com todo o caso do qual ela, por outro lado, queixava-se. Daí o manejo de Freud ao levar Dora a reconhecer, de forma consciente, que ela também estava implicada em toda aquela desordem causada. Para a educação, o professor poderia se posicionar de modo semelhante, levando o educando a se perceber como parte integrante do seu aprendizado, implicando-o a construir, por meio da interação, da troca de conhecimento, das experiências, seu aprendizado, com autonomia e responsabilidade. $\mathrm{O}$ educador necessita ter em mente que não pode aceitar tudo do educando como se o que ele faz fosse, em sua totalidade, maravilhoso. $\mathrm{O}$ professor não pode ceder frente às reclamações e queixas - quando não justas - dos alunos. Precisa colocá-los para trabalhar e trabalhar com eles a partir dos pontos de impasses que aparecem no trabalho com a língua escrita. Quando se trata de aprender a ler e a escrever, devemos reconhecer que a maior parte do trabalho deve ser feita pelo próprio aluno, tendo o professor como o guia nessa grande aventura.

Essa conduta nos parece das mais importantes porque ao fim e ao cabo o que cada aluno precisa, do ponto de vista da alfabetização e do letramento em Língua Portuguesa, é aprender a saber-fazer com a língua, esta nas suas mais diversas manifestações no mundo dos homens. Não aprenderá se a ênfase escolar não recair no fazer, e para isso o professor e o aluno precisam suportar a angústia desse processo: o aluno certamente sempre irá se queixar e concentrar todos os esforços para evitar, ele mesmo, se implicar nesse processo, preferindo vê-lo apenas como responsabilidade do professor. É importante, contudo, que o professor envide não apenas esforço pedagógico, mas também ético, no sentido de instaurar, com seus alunos, processos de alfabetização e letramento capazes de prepará-los para os usos efetivos da língua escrita como cidadãos plenos. Implicar para responsabilizar, esse era o posicionamento de Freud. Nesse sentido, afirma Jorge Forbes: "Freud já se preocupava com a questão da responsabilidade por aquilo que é inconsciente; um exemplo é o caso Dora, quando ele a implicava para que veja qual é a sua parte na desordem de que ela se queixa" (FORBES, 2012, p. XIV). 
Como já dito, Dora, a paciente em questão, responsabilizava a todos pela desordem pela qual sua família passava, mas não reconhecia sua quota participação nisso tudo, daí sua queixa, que lhe parecia justa, e sua irresponsabilidade subjetiva frente ao que lhe ocorria. Do ponto de vista da alfabetização e do letramento, não raro os alunos, suas famílias e mesmo a sociedade adotam comportamento queixoso, frequentemente contra os professores. Nessa direção, poderíamos dizer, com o poeta Carlos Drummond de Andrade: os ombros dos professores suportam o mundo. Preciso é, pois, deslocar a queixa, por meio da implicação, para o polo da responsabilidade: responsabilizar os alunos pela construção de seu próprio conhecimento, tendo o professor como parceiro mais experiente nessa jornada. Desde sempre, o professor precisa deixar claro que não dará o conhecimento ao aluno, mas que o ajudará na construção de seu próprio. No campo da Psicanálise, esse também era o posicionamento de Lacan, que adotava o método freudiano de implicar seus pacientes.

Além disso, na transmissão da Psicanálise, ele desejava que cada um de seus leitores se implicasse no conhecimento que estava construindo ao ler seus textos. Isso pode ser visto no texto de abertura de sua coletânea Escritos, quando diz: "queremos, com o percurso de que estes textos são os marcos e com o estilo que seu endereçamento impõe, levar o leitor a uma consequência em que ele precise colocar algo de si" (LACAN, 1998, p. 11). Quando Lacan diz colocar algo de si, implica o leitor em sua própria leitura, ou seja, que ele procure não apenas reproduzir, mas produzir uma leitura que não fique apenas na superfície do já dito, mas que vá além, que testemunhe a assinatura daquele que lê.

Levando essa compreensão para o ensino, o professor precisa também fazer com que seu aluno coloque sempre de si em suas produções, instaurando marcas de autoria, e isso desde muito cedo. No que diz respeito ao processo de ensino-aprendizagem, especificamente sobre o letramento, a Psicanálise contribui dizendo que o professor precisa fazer com que o aluno se implique na prática do saber fazer, ou seja, levar o aluno a dar de si, a responsabilizar-se por seu aprendizado, a trabalhar para construir seu conhecimento, e não se fixar em posições ruins, como a da queixa estéril de que quando se não aprende a responsabilidade é do professor. Agindo assim, leva o educando a se perceber como parte desse processo de aprendizagem e, nesse sentido, é interessante o não compreender e o não aceitar tudo o que ele fizer, implicando-o a buscar melhorar sua prática do bem dizer.

Quanto à escrita, isso significa dizer que o professor não deve cair na armadilha de tentar adivinhar o que o aluno quer dizer quando escreve textos incompreensíveis. A escola é 
o lugar em que o aluno deve aprender a ler e a escrever bem e, para tanto, deve passar pelo mar da angústia do trabalho de escrita, como bem aponta Riolfi (2015). Por isso, é importante que o professor devolva com o aluno a escuta daquilo que escreveu: a sua escrita condiz com o que havia planejado, ou seja, foi realmente para o papel o que tinha na cabeça? Em caso negativo, o aluno deve trabalhar para conseguir bem dizer, por meio da escrita, o que formulou no pensamento. Entendemos que, por meio desse trabalho, o educando desenvolve a leitura e a escrita para além do alfabetismo funcional, tornando-se letrado. Para isso, é necessário que o professor também se torne exemplo na prática cotidiana tanto da leitura quanto da escrita, para que o seu aluno se sinta motivado nesse processo. Nessa perspectiva, o professor só conseguirá guiar os alunos se eles mesmos já tiverem experimentado o percurso. Como dizia Freud no texto Análise terminável e interminável, o analista só consegue levar o analisando até o ponto onde ele mesmo levou sua própria análise. Similarmente, o professor, se não escreve e não lê, tentará em vão levar os alunos a trilharem o caminho do letramento.

\section{Considerações finais}

Neste trabalho tentamos elaborar uma pequena contribuição ao campo da alfabetização e do letramento na educação infantil, trazendo ao diálogo a Psicanálise freudo-lacaniana. A ideia central girou em torno de como a Psicanálise contribui de modo positivo para o desenvolvimento desses processos dentro da sala de aula, especificamente sobre como o professor pode adotar uma atitude ética de implicar o aluno para que ele se perceba como parte fundamental na construção do seu próprio aprendizado. Podemos concluir que, se o professor adotar essa postura de implicação e responsabilização, os processos de leitura e escrita na educação infantil poderão se desenvolver não apenas na perspectiva da alfabetização, mas também do letramento, tornando o trabalho pedagógico bastante significativo tanto para o educador quanto para o educando. De modo bastante claro, compreendemos que o letramento é o uso social da leitura e da escrita e da capacidade de alcançar os diferentes objetivos nas mais variadas esferas sociais e culturais nas quais estamos inseridos. É, por assim dizer, o saber fazer com a língua escrita efetivamente dentro e fora da escola.

Compreendemos que a Psicanálise permite ao educador implicar o seu educando no processo de ensino e aprendizagem de maneira pertinente, isto é, levá-lo a perceber-se como parte fundamental na busca do seu conhecimento e nas diversas práticas do saber fazer, dando 
o melhor de si com responsabilidade e buscando sempre aprimorar seu desenvolvimento. Ficou patente que, para essa finalidade, o professor deve se colocar como exemplo de empenho e responsabilidade, ou seja, não apenas cobrando do aluno, mas fazendo junto com ele.

\section{Referências}

CAGLIARI, Luiz Calos. Alfabetizando Sem o BÁ-BÉ-BI-BÓ-BU. São Paulo: Scipione, 1998. FERREIRO, Emília; TEBEROSKY, Ana. Psicogênese da língua escrita. Porto Alegre: Artes Médicas, 1999.

FORBES, Jorge. Inconsciente e responsabilidade. São Paulo: Manole, 2012.

FREUD, Sigmund. Análise terminável e interminável. In: FREUD, S. Edição Standard Brasileira das obras psicológicas completas de Sigmund Freud. Vol. 23. Rio de Janeiro: Imago, 2019, p. 239-287.

FREUD, Sigmund. Fragmento da Análise de um caso de Histeria. Caso Dora. In: FREUD, Sigmund. Edição Standart Brasileira das Obras Psicológicas Completas de Sigmund Freud. Vol. VII. Rio de Janeiro: Imago, 2019, p. 15-108.

LACAN, Jacques. Escritos. Rio de Janeiro: Zahar, 1998.

RIOLFI, C. R. A língua espraiada. Campinas, SP: Mercado de Letras, 2015.

SOARES, Magda. Alfabetização: a questão dos métodos. São Paulo: Contexto, 2007.

SOARES, Magda. Letramento e escolarização. In: RIBEIRO, Vera Masagão (Org.).

Letramento no Brasil. São Paulo: Global, 2003. p. 89-115

SOARES, Magda. Letramento: um tema em três gêneros. Belo Horizonte: Autêntica, 1998. TFOUNI, Leda Verdiani. Letramento e alfabetização. 7. ed. São Paulo: Cortez, 2005. 